The Agriculturists 15(1):110-115(2017) ISSN 2304-7321 (Online), ISSN 1729-5211 (Print)

\title{
Evaluation of Aus Rice (Oryza sativa L.) Production in Less Irrigated Situation in Northern Region of Bangladesh
}

\author{
M. Sh. Islam ${ }^{1}$, A.B.M. Zahid Hossain ${ }^{2}$, M.S. Miah ${ }^{3}$, S.M. Shahriar ${ }^{3}$ and M.A.A. Mamun ${ }^{4}$ \\ ${ }^{1}$ Agronomy Division, ${ }^{2}$ Irrigation and Water Management Division, ${ }^{4}$ Agricultural Statistics Division, \\ Bangladesh Rice Research Institute (BRRI), Gazipur-1701, Bangladesh \\ ${ }^{3}$ IAPP Project, BRRI Rangpur, Bangladesh \\ *Corresponding author and Email: shahidul.brri@yahoo.com
}

Received: 2 March 2017

Accepted: 12 June 2017

\begin{abstract}
Twenty one demonstrations and two validation trials were carried out at the farmers' field in the northern region of Bangladesh during 2014 using Aus rice: variety BRRI dhan 48 to enhance Aus (pre-monsoon) rice cultivation. Grain yields of 3.5 to $6.5 \mathrm{t} \mathrm{ha}^{-1}$ were obtained from demonstrations plots conducted in different farmers' field. The validation trial was conducted in the farmers' field at Mithapukur and Nilphamari Sadar Upazillas using BRRI dhan28 and BRRI dhan48 as Braus (rice grown between Boro and Aus season) after harvesting potato. Grain yield of about $5.0 \mathrm{t} \mathrm{ha}^{-1}$ was obtained from the rice variety BRRI dhan28, while $6.6 \mathrm{t} \mathrm{ha}^{-1}$ was obtained from BRRI dhan 48 . BRRI dhan 48, due to its shorter growth duration (100-105 days) required 2-3 less irrigations. About 28-36\% less irrigation water was required during dry season when BRRI dhan 48 was used as Braus instead of BRRI dhan 28 as a Boro crop. About 20 to $60 \%$ higher grain yield was observed in different farmers' field with BRRI dhan 48 over BRRI dhan28, which indicated that BRRI dhan 48 is a potential rice variety during Aus or Braus season. BRRI dhan48 can be cultivated after Boro harvest or as Braus after potato harvest. The variety could also decrease the pressure on ground water utilization for rice cultivation during dry season.
\end{abstract}

Keywords: BRRI dhan48, Braus, Climate change.

\section{Introduction}

Boro (dry season) rice (Oryza sativa L.) -FallowT. aman (monsoon rice) cropping pattern is dominant in Rangpur region of northern Bangladesh, where about $40 \%$ of cultivable land is comprised of this pattern. Farmers are growing boro rice in medium high land by irrigating more than 20 times in a season. Thus, boro cultivation is costly due to high water consumption (Nargis et al., 2009). In Bangladesh, ground water is decreasing day by day due to climate change, less rainfall, less recharge of ground water (Hodgson et al., 2014). Nevertheless with the rising water stress and erratic rainfall, Bangladesh Government has been trying to reduce the Boro rice cultivation in the country for last few years. Aus (premonsoon season) rice production between Rabi (dry season) and Kharif II (Braus) might be an alternate to save underground water. Production of short duration rain-fed Aus rice is a good step to conserve ground water (Roy et al., 2013).

Farming of Aus crop area using unused seasonal rain water must be increased during the Kharif-1 
season as an additional and substitute cereal crop to gradually replace cultivation of more irrigation water consuming and costly Boro farming (Rahman et al., 2016). Hence groundwater utilization will be reduced in Rangpur region under climate change situation and food security will be stable with the upscaling of Aus instead of Boro rice. At present, the Aus area in Rangpur region is about 9\% (Personal communication with $\mathrm{DD}$ and $\mathrm{AD}$ of DAE, Rangpur). The government has given a thrust on Aus rice cultivation by distributing seeds, fertilizers etc. among the farmers of Bangladesh. The present study was undertaken to evaluate the yield performance of Aus rice, variety BRRI dhan 48 and estimate the irrigation water requirement of the Aus rice compared to Boro rice at the farmers' field of Rangpur.

\section{Materials and Methods}

Thirty five farmers of seven villages namely Bagerbazar of Pirgonj, Rangpur Batason Durgapur of Mithpukur, Rangpur, Fulgas of Lalmonirhat Sadar, Surpukur of Aditmari, Lalmonirhat, Sundra Hobi of Kaligonj, Lalmonirhat Amtoli of Rajarhat, Kurigram and Ponchapukuri of Nilphamari Sadar were selected in Rangpur region to introduce BRRIdhan48 as against local varieties like Parija, Vhadi etc. Selected lands were medium-high and the type of soil was light textured.

\subsection{Cultivation methods}

Rice seeds of BRRI dhan48 was collected from BRRI Rangpur. Land was prepared by the respective farmers and basal fertilizers was applied @ of 60,75, and 45 kg per ha, TSP, MoP and gypsum, respectively and urea was applied @ $180 \mathrm{~kg}$ per ha at 12 \& 25 DAT following BRRI recommendation. Adaptive trial of Braus was conducted in potato growing area (Mithapukur and Nilphamari Sadar Upazilla) after harvesting potato. The most popular Boro variety BRRI dhan 28 and Aus variety BRRI dhan 48 were used in the adaptive trial in Braus. The seeding date was $1^{\text {st }}$ week of February and transplanting date was $2^{\text {nd }}$ week of March, 2014. Thirty five days old seedlings were transplanted for both the varieties. BRRI recommended cultural practices like weed management, irrigation, pest management were done as and when necessary.

\subsection{Data collection and analysis}

The data on plant height, panicle $\mathrm{m}^{-2}$, grain panicle $^{-1}$, growth duration and grain yield were collected from rice plants of $5 \mathrm{~m} \times 2 \mathrm{~m}$ area from each plot with 3 replications. The grain moisture was measured just after threshing and grain yield was adjusted at $14 \%$ moisture content. Combined analysis (Programing R) was done to find out the interaction effect of genotype $\times$ environment for 21 demonstrations on BRRI dhan 48 in different locations of Rangpur.

\section{Results and Discussion}

The average plant height was $103 \mathrm{~cm}$, average panicle $\mathrm{m}^{-2}$ was 275 , average grain panicle ${ }^{-1}$ was 88 and average grain yield was $4.50 \mathrm{t} \mathrm{ha}^{-1}$ (Table 1). Grain yield performance was higher $(5.97 \mathrm{t}$ $\mathrm{ha}^{-1}$ ) after potato harvest (Table 2).

\subsection{Genotype $\times$ Environment effect}

Based on combined analysis of variance the individual effect of genotypes and locations were highly significant (1\% level) and the interaction effect of genotype and location was significant (5\% level). BRRI dhan48 showed different performance in different locations. The yield performance was not stable over the locations. The CV value was $9.4 \%$ which indicated that the experiment was perfectly designed and the precision levels was satisfactory (Table 3 ). The reliability of the data were acceptable.

\subsection{Validation trial on BRRI dhan 28 and BRRI dhan48 in Rangpur and Nilphamari}

Table 4 shows that the highest grain yield $(6.71 \mathrm{t}$ $\mathrm{ha}^{-1}$ ) was observed in BRRI dhan 48 at 
Mithapukur and the lowest yield $\left(4.22 \mathrm{t} \mathrm{ha}^{-1}\right)$ was observed in BRRI dhan28 at Nilphamari Sadar. Yield performance of BRRI dhan28 at Mithapukur and BRRI dhan28 and 48 in
Nilphamari Sadar was statistically similar. So, in Rangpur region after potato harvest BRRI dhan 48 could be cultivated as Barus season for higher yield in respective of cropping pattern.

Table 1. Plant height, panicle no. $\mathrm{m}^{-2}$, grains no. panicle $\mathrm{e}^{-1}$ and grain yield of BRRI dhan 48 as influenced by different locations during Aus 2014 at Rangpur region

\begin{tabular}{lcccccc}
\hline Location & $\begin{array}{c}\text { Demo } \\
\text { no. }\end{array}$ & $\begin{array}{c}\text { Plant ht. } \\
(\mathrm{cm})\end{array}$ & $\begin{array}{c}\text { Panicle } \\
\text { no. } \mathrm{m}^{-2}\end{array}$ & $\begin{array}{c}\text { Grain } \\
\text { no.panicle }\end{array}$ & $\begin{array}{c}1000 \\
\mathrm{GW}(\mathrm{g})\end{array}$ & $\begin{array}{c}\text { Yield } \\
\left(\mathrm{t} \mathrm{ha}^{-1}\right)\end{array}$ \\
\hline $\begin{array}{l}\text { Bagerbazar } \\
\text { Lalmonirhat }\end{array}$ & 2 & $106^{* *}$ & $310 \mathrm{a}^{*}$ & $92 \mathrm{ab}$ & $24.7 * *$ & $6.04 \mathrm{a}$ \\
$\quad$ Sadar & 3 & 102 & $273 \mathrm{bc}$ & $77 \mathrm{bc}$ & 24.1 & $3.73 \mathrm{~b}$ \\
$\begin{array}{l}\text { Aditmari } \\
\text { Kaligonj }\end{array}$ & 3 & 103 & $265 \mathrm{~cd}$ & $71 \mathrm{c}$ & 23.8 & $3.37 \mathrm{~b}$ \\
$\begin{array}{l}\text { Rajarhat, } \\
\text { Kurigram }\end{array}$ & 1 & 102 & $254 \mathrm{~cd}$ & $68 \mathrm{c}$ & 23.7 & $3.10 \mathrm{~b}$ \\
$\quad \begin{array}{l}\text { Nilphamari } \\
\text { Sadar }\end{array}$ & 103 & $293 \mathrm{ab}$ & $99 \mathrm{a}$ & 24.5 & $5.58 \mathrm{a}$ \\
* In column, mean with same letter (s) are not differed significantly at 5\% level of significance, ** NS
\end{tabular}

Table 2. Plant height, panicle $\mathrm{m}^{-2}$, grains panicle ${ }^{-1}$ and grain yield of BRRI dhan 48 as influenced by different cropping pattern during Aus 2014, Rangpur region

\begin{tabular}{lccccc}
\hline Cropping Pattern & $\begin{array}{c}\text { Demo } \\
\text { no. }\end{array}$ & $\begin{array}{c}\text { Plant ht. } \\
(\mathrm{cm})\end{array}$ & $\begin{array}{c}\text { Panicle no. } \\
\mathrm{m}^{-2}\end{array}$ & $\begin{array}{c}\text { Grain } \\
\text { no.panicle }^{-1}\end{array}$ & $\begin{array}{c}\text { Yield } \\
\left(\mathrm{t} \mathrm{ha}^{-1}\right)\end{array}$ \\
\hline After Boro harvest & 4 & $102^{* *}$ & $256 \mathrm{~b}^{*}$ & $87 \mathrm{abc}$ & $3.96 \mathrm{bc}$ \\
After damaged Boro & 1 & 102 & $296 \mathrm{a}$ & $92 \mathrm{ab}$ & $4.60 \mathrm{~b}$ \\
After potato harvest & 8 & 104 & $302 \mathrm{a}$ & $100 \mathrm{a}$ & $5.97 \mathrm{a}$ \\
After sunflower harvest & 1 & 101 & $252 \mathrm{~b}$ & $68 \mathrm{c}$ & $3.10 \mathrm{c}$ \\
After tobacco harvest & 7 & 102 & $257 \mathrm{~b}$ & $78 \mathrm{bc}$ & $3.31 \mathrm{c}$ \\
\hline CV\% & \multicolumn{7}{c}{1.54} & 9.65 & 15.21 & 29.24 \\
\hline In column, means with same letter (s) are not differed significantly at 5\% level of significance, **NS
\end{tabular}

Table 3. Combined analysis for grain yield of BRRI dhan48, Aus 2014, Rangpur

\begin{tabular}{lccccc}
\hline S.V & Df & Sum Sq & Mean Sq & F value & $\operatorname{Pr}(>$ F $)$ \\
\hline Genotype (G) & 1 & 5.7241 & 5.7241 & 24.8793 & $0.002482 * *$ \\
Location (L) & 1 & 6.5921 & 6.5921 & 28.652 & $0.001740 * *$ \\
L:R & 6 & 1.9597 & 0.3266 & 1.4196 & 0.340637 \\
G:L & 1 & 2.1536 & 2.1536 & 9.3603 & $0.022240 *$ \\
Residuals & 6 & 1.3804 & 0.2301 & & \\
\hline
\end{tabular}

$\mathrm{R}=$ Replication, $\mathrm{CV} \%=9.4$, Mean $=5.098, \mathrm{LSD}=0.587$ 
Table 4. Grain yield of two varieties in Mithapukur and Nilphamari Sadar during Braus season 2014, Rangpur

\begin{tabular}{lcc}
\hline \multirow{2}{*}{ Location } & \multicolumn{2}{c}{ Yield (t ha $\left.{ }^{-1}\right)$} \\
\cline { 2 - 3 } & BRRI dhan48 & BRRI dhan28 \\
\hline Mithapukur & $6.71 \mathrm{a}^{*}$ & $4.78 \mathrm{~b}$ \\
Nilphamari Sadar & $4.69 \mathrm{~b}$ & $4.23 \mathrm{~b}$ \\
\hline * In column, means with same letter (s) are not differed significantly at 5\% level of significance.
\end{tabular}

Table 5. Irrigation number required for BRRI dhan 28 and BRRI dhan48 during Braus 2014 season

\begin{tabular}{|c|c|c|c|c|c|c|c|c|c|c|}
\hline \multirow{2}{*}{$\begin{array}{l}\text { De } \\
\text { mo } \\
\text { no. }\end{array}$} & \multicolumn{2}{|c|}{ No of irrigation } & \multicolumn{2}{|c|}{$\begin{array}{l}\text { Applied water } \\
(\mathrm{mm})\end{array}$} & \multirow{2}{*}{$\begin{array}{c}\text { Rainf } \\
\text { all } \\
(\mathrm{mm})\end{array}$} & \multicolumn{2}{|c|}{$\begin{array}{l}\text { Total water } \\
\quad(\mathrm{mm})\end{array}$} & \multicolumn{2}{|c|}{$\begin{array}{l}\text { Yield } \\
\left(\mathrm{t} \mathrm{ha}^{-1}\right)\end{array}$} & \multirow{2}{*}{$\begin{array}{c}\% \\
\text { increase } \\
\text { over } \\
\text { BRRI } \\
\text { dhan28 }\end{array}$} \\
\hline & $\begin{array}{c}\text { BRRI } \\
\text { dhan28 }\end{array}$ & $\begin{array}{c}\text { BRRI } \\
\text { dhan48 }\end{array}$ & $\begin{array}{c}\text { BRRI } \\
\text { dhan28 }\end{array}$ & $\begin{array}{c}\text { BRRI } \\
\text { dhan48 }\end{array}$ & & $\begin{array}{c}\text { BRRI } \\
\text { dhan28 }\end{array}$ & $\begin{array}{c}\text { BRRI } \\
\text { dhan48 }\end{array}$ & $\begin{array}{c}\text { BRRI } \\
\text { dhan28 }\end{array}$ & $\begin{array}{c}\text { BRRI } \\
\text { dhan48 }\end{array}$ & \\
\hline & \multicolumn{10}{|c|}{ Mithapukur, Rangpur } \\
\hline 1 & 15 & 13 & 543 & 471 & 390 & 933 & 861 & 5770 & 6940 & 20.15 \\
\hline 2 & 15 & 13 & 573 & 496 & 390 & 963 & 886 & 5450 & 6560 & 20.49 \\
\hline 3 & 15 & 13 & 573 & 496 & 390 & 963 & 886 & 4180 & 6670 & 59.57 \\
\hline 4 & 15 & 12 & 591 & 473 & 390 & 981 & 863 & 3700 & 6650 & 79.76 \\
\hline 5 & 13 & 13 & 546 & 546 & 390 & 936 & 936 & 5590 & 6180 & 10.57 \\
\hline 6 & 13 & 13 & 512 & 512 & 390 & 902 & 902 & 4160 & 6730 & 61.70 \\
\hline 7 & 15 & 13 & 588 & 510 & 390 & 978 & 900 & 5740 & 6650 & 15.91 \\
\hline 8 & 15 & 13 & 525 & 455 & 390 & 915 & 845 & 5510 & 6660 & 20.97 \\
\hline 9 & 15 & 14 & 591 & 551 & 390 & 981 & 941 & 4280 & 6650 & 55.10 \\
\hline \multirow[t]{3}{*}{10} & 15 & 14 & 591 & 551 & 390 & 981 & 941 & 5130 & 6700 & 30.60 \\
\hline & \multicolumn{5}{|c|}{ Average } & 953 & 896 & 4951 & 6639 & 37.48 \\
\hline & \multicolumn{10}{|c|}{ Nilphamari Sadar } \\
\hline 1 & 15 & 13 & 633 & 548 & 360 & 993 & 908 & 4250 & 5050 & 18.80 \\
\hline 2 & 15 & 13 & 578 & 501 & 360 & 938 & 861 & 4050 & 4350 & 7.40 \\
\hline 3 & 15 & 13 & 584 & 506 & 360 & 944 & 866 & 4350 & 4750 & 9.20 \\
\hline 4 & 15 & 12 & 574 & 459 & 360 & 934 & 819 & 4250 & 4600 & 8.20 \\
\hline \multicolumn{6}{|c|}{ Average } & 952 & 864 & 4225 & 4688 & 10.90 \\
\hline
\end{tabular}

Table 5 also showed that about 12 to 15 number of irrigation was required for Braus cultivation as there was rainfall of $360-390 \mathrm{~mm}$ during March-May. BRRI dhan48 received 2-3 number of less irrigation in most cases due to shorter growth duration as compared to BRRI dhan 28 . In this region, average $864-896 \mathrm{~mm}$ of water required (Mainuddin et al., 2014) for cultivating BRRI dhan48, whereas BRRI dhan28 required about $953 \mathrm{~mm}$ of water (Table 5). Over aged seedlings need more irrigations to overcome transplanting shock for BRRI dhan 28 at vegetative stage. So, BRRI dhan 28 required more irrigation water than BRRI dhan 48 .

Figure 1 and 2 showed the comparative water requirement for both the varieties in Rangpur region. BRRI dhan 28 and BRRI dhan 48 were 
transplanted under irrigated condition due to lack of rainfall during March in Rangpur region (Fig. $1 \& 2$ ). Irrigation requirement depends on rainfall and reference crop evapo-transpiration. No irrigation water was applied during the month of June due to sufficient rainfall. So, evaporative demand of crops minimized through rainwater. In the month of May, irrigation requirement was much lower than the month of April due to much lower evaporation demand that could be provided from rainfall for both the varieties (Figs. $1 \& 2$ ).

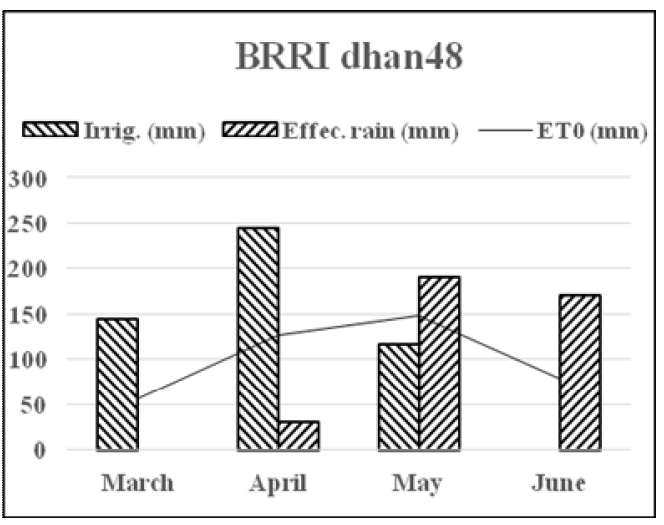

If BRRI dhan 28 was cultivated as a Boro variety in proper time, considering conventional irrigation practice then 20-25 number of irrigation water was required in this region which was about $1630-1744 \mathrm{~mm}$ of water (BRRI 2012-13) and also yield of BRRI dhan 48 as Braus obtained more or less similar to BRRI dhan 28 as Boro. Boro rice, an irrigated crop, consumed 73 percent of the total crop irrigation and contributed to a greater extent in total rice production in Bangladesh (Rahman et al., 2009).

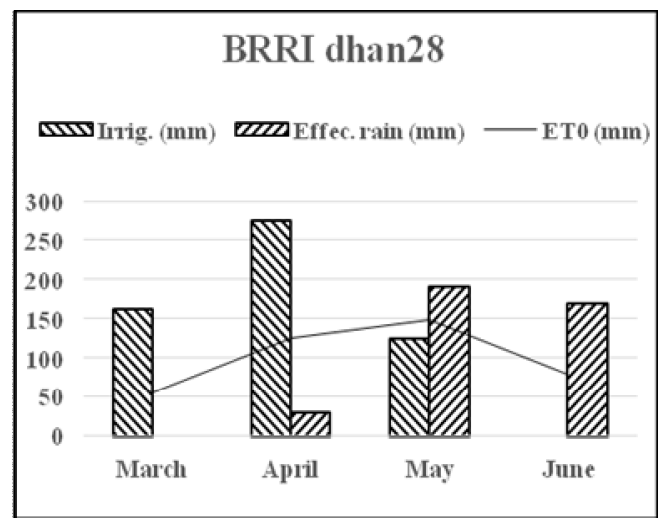

Figure 1. Monthly effective rainfall, reference crop evapotranspiration $\left(\mathrm{ET}_{0}\right)$ and irrigation water for BRRI dhan 48 and BRRI dhan28 at Mithapukur, Rangpur district
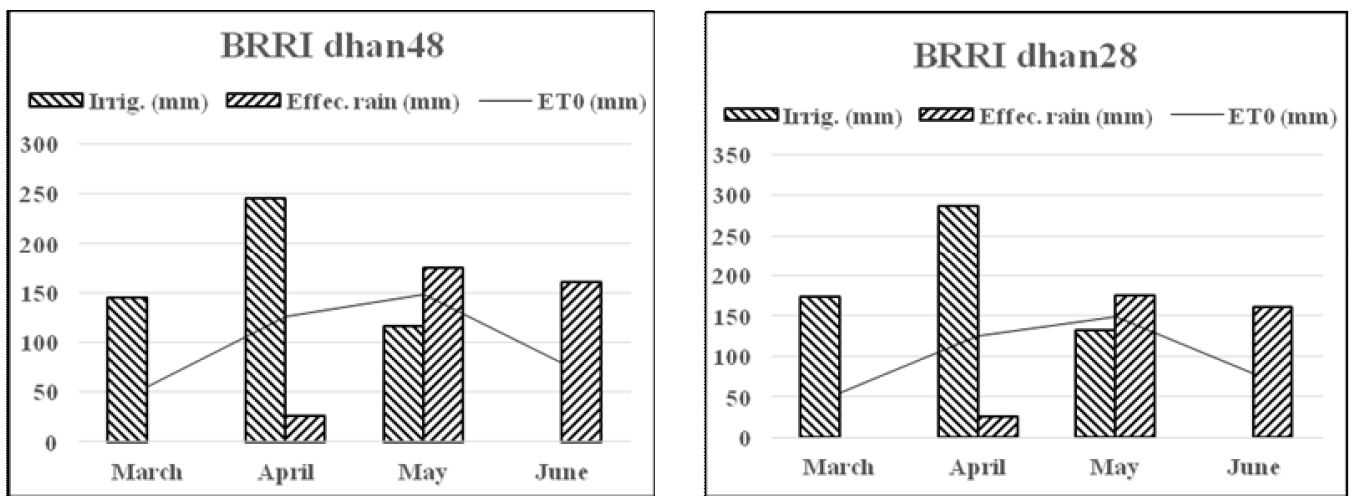

Figure 2. Monthly effective rainfall, reference crop evapotranspiration $\left(\mathrm{ET}_{0}\right)$ and irrigation water for BRRI dhan48 and BRRI dhan28 at Sadar, Nilphamari district 
So, if BRRI dhan 48 was cultivated as late Boro or Braus instead of BRRI dhan 28 as Boro then it can save about 28-36 percent of irrigation water. Thus, it was clear from the results that in late Boro or as Braus, BRRI dhan48 is the best variety compared to BRRI dhan28. Badshah et al. (2013) also reported that BRRI dhan 28 gave lower grain yield when it was planted 15 February and 15 March compared to hybrid varieties. Therefore, groundwater utilization can be reduced during Boro season in this region by cultivating BRRI dhan 48 as Braus rice. This is a good alternative to save ground water in the climate change situation and also to ensure food security. It was also observed that the grain yield of BRRI dhan 48 was higher when cultivated after potato compared to tobacco, which was mainly due to aggressive nutrient uptake by tobacco.

\section{Conclusions}

Potato-BRRI dhan48 - T.Aman might be the potential and profitable cropping pattern in medium lowland to medium highland area (about $80 \%$ ) of Rangpur region. BRRI dhan 48 is the best variety as late Boro compared to BRRI dhan28.

\section{Acknowledgement}

Authors are grateful to IAPP Project Management for financial support to complete the study and to Mr. Roydurlov and P K Borman for taking data from the farmers' field.

\section{References}

BRRI 2013. Bangladesh Rice Research Institute Annual Research Review Workshop Report of IWM Division, 2012- 13, pp 49-50.

Nargis, F., Miah, T.H., Khanam, T.S. and Sarwer, R.H. 2009. Profitability of MV Boro rice production under shallow tubewell irrigation system in some selected areas of Tangail district. Progressive Agriculture, 20(1\&2): 237-244.
Badshah M.A and Ali, M.H. 2013. Yield performance of some exotic hybrid rice at different dates of planting in the northern part of Bangladesh. International Journal of Bio-Resources, 15(4):1-6.

Hodgson G., Ali, R., Turner, J., Ahmad M., Hossain, W.M.J., Alam, S. and Islam, M.M. 2014. Bangladesh Integrated Water Resources Assessment supplementary report: Groundwater trends in Bangladesh. A report to the CSIRODFAT Alliance.

Mainuddin M., Kirby, M., Chowdhury, R.A.R., Sanjida, L. Sarker, M.H. and ShahNewaz, S.M. 2014. Bangladesh Integrated Water Resources Assessment supplementary report: land use, crop production, and irrigation demand. A report to the CSIRO-DFAT Alliance.

Rahman, A. Kamruzzaman, T.M.S., Jahan, M.C.S., Mazumder, Q.H. and Hossain, A. 2016. Evaluation of spatio-temporal dynamics of water table in NW Bangladesh: an integrated approach of GIS and Statistics. Sustainable Water Resources and Management, 2( 3): 297312.

Rahman, M. W. and Lovely Parvin, 2009. Impact of Irrigation on Food Security in Bangladesh for the Past Three Decades. Journal of Water Resource and Protection, 3:216-225.

Roy, B.P, Ali, M.G., Iftekharuddulah, K.M. and Islam, M.J. 2013. The Prospect of BRRI dhan 48 cultivation to face climate change. The folder published by IAPP (R/S Rangpur). 